\title{
DESEMPENHO DE Oreochromis niloticus TESTANDO DIFERENTES GRANULOMETRIAS DE RAÇÃO DE ACORDO COM O DESENVOLVIMENTO BUCAL
}

\author{
Oreochromis niloticus performance testing of different granules sizes in \\ crumble diets according to the oral development
}

\author{
Laura Satiko Okada Nakaghi ${ }^{[a]}$, Carla Fredrichsen Moya ${ }^{[b]}$, \\ Teresa Cristina Ribeiro Dias-Koberstein ${ }^{[c]}$, Sérgio Fonseca Zaiden ${ }^{[\mathrm{d}]}$, \\ Maria do Carmo Faria Paes ${ }^{[\mathrm{e}]}$, Lilian Cristina Makino ${ }^{[\mathrm{f}]}$
}

\footnotetext{
[a] Médica Veterinária, professora Livre-Docente do Departamento de Morfologia e Fisiologia Animal da Faculdade de Ciências Agrárias e Veterinárias (FCAV), Universidade Estadual Paulista (UNESP), Jaboticabal, SP - Brasil, e-mail: laurankg@fcav.unesp.br

${ }^{[b]}$ Médica Veterinária, professora Doutora das Faculdades Integradas de Ourinhos (FIO), Ourinhos, SP - Brasil, e-mail: carlafredrichsen@yahoo.com.br

[c] Zootecnista, Doutora, Pesquisadora do Centro de Aquicultura da Universidade Estadual de São Paulo (UNESP), Jaboticabal, SP - Brasil, e-mail: crisdias@caunesp.unesp.br

[d] Zootecnista, Doutor, professor Titular da Fundação de Ensino Superior de Rio Verde-GO (FESURV), Rio Verde, GO - Brasil, e-mail: sfzaiden@hotmail.com

${ }^{[e]}$ Bióloga, Doutoranda do Programa de Pós-graduação em Aquicultura do Centro de Aquicultura da Universidade Estadual Paulista (UNESP), Jaboticabal, SP - Brasil, e-mail: mariacfpaes@yahoo.com.br

${ }^{[f]}$ Médica Veterinária, Doutora do Programa de Pós-graduação em Aquicultura do Centro de Aqüicultura da Universidade Estadual Paulista (UNESP), Jaboticabal, SP - Brasil, e-mail: lilianmakino@yahoo.com.br
}

\begin{abstract}
Resumo
O cultivo da tilápia nilótica vem crescendo em países como o Brasil, devido às suas características zootécnicas, que são ótimas para a produção piscícola: crescimento rápido, aceitação de rações balanceadas, carne de excelente qualidade, facilidade na industrialização e filetagem, ausêncía de espinhos intramusculares, resistência ao manejo intensivo e também às doenças. Considerando a importância dessa espécie para a piscicultura e a falta de dados morfofuncionais do seu aparato bucal na fase larval, o trabalho teve como objetivo estudar o desenvolvimento bucal com o intuito de fornecer subsídios para avaliar a eficiência da utilização de rações com granulometrias adequadas. O experimento foi realizado em duas etapas: na primeira parte foi analisado o desenvolvimento bucal, com o auxílio da microscopia eletrônica de varredura; a segunda parte do experimento consistiu no teste de três granulometrias de ração, que foram: $0,21 \mathrm{~mm}, 0,35$ $\mathrm{mm}$ e $0,50 \mathrm{~mm}$. Aos 35 dias de idade, realizou-se a biometria dos alevinos, que foram pesadas e medidas. Os resultados mostraram que as larvas de tilápia eclodiram com a boca fechada e o
\end{abstract}

Rev. Acad., Ciênc. Agrár. Ambient., Curitiba, v. 7, n. 4, p. 415-421, out./dez. 2009 
momento da abertura foi, em média, de 24 horas após a eclosão. Nos dados biométricos verificou-se que o uso das rações com granulometrias $0,35 \mathrm{~mm}$ e $0,50 \mathrm{~mm}$ apresentaram os melhores resultados de desempenho.

Palavras-chave: Boca. Granulometria. Larva. Morfometria. Ração. Ttilápia-do-Nilo.

\begin{abstract}
Nile tilapia cultivation of has been increasing in several countries such as Brazil, due to its zootechnical features that yield profitable fish production: fast growth, acceptance of balanced commercial diets, high-quality meat, easier industrialization and fillet cutting, absence of muscular spines, resistance to both intensive handling and diseases. Considering the importance of this species in the fish culture and the lack of morphofunctional data about the oral apparatus during larval stages, the foal of the present work was to describe the oral cavity development in order to provide subsidies to evaluate the efficiency of using crumble diets with adequate granule sizes. The experiment was carried out in two stages: firstly, we analyzed the oral development period by using scanning electron microscopy; secondly, we tested three granule diameters in crumble diet, as follows: $0.21 \mathrm{~mm}, 0.35 \mathrm{~mm}$ and $0.50 \mathrm{~mm}$. At 35 days of age, larval biometry was performed and they were weighed and measured. The results showed that the mouth of recently-hatched Nile tilapia larvae is closed and it becomes open 24 hours after hatching, in average. Based on biometric data, we verified that crumble diets with granule sizes of 0.35 and $0.50 \mathrm{~mm}$ yielded the best performance results.
\end{abstract}

Keywords: Mouth. Granule sizes. Larva. Morphometry. Diet. Nile tilapia.

\title{
INTRODUÇÃO
}

A criação de peixes em tanques e lagos tem tido uma grande importância em países de clima tropical e subtropical como o Brasil, tanto como fonte de renda como de proteína. Nesse contexto, a tilápia é a espécie de água doce mais utilizada nos cultivos comerciais, principalmente por sua rusticidade, rápido crescimento, carne de ótima qualidade e boa aceitação no mercado consumidor, facilidade na industrialização e filetagem, ausência de espinhos intramusculares, resistência ao manejo intensivo e às doenças (LEONHARDT; URBINATTI, 1999).

A tilápia é um dos peixes mais comercializados atualmente e seu mercado vem se ampliando a cada dia, com crescentes números de exportação, tanto na forma de filés frescos quanto congelados. É criada em diversos países e, somada a outros ciclídeos, atinge uma produção anual estimada em 26.768.131 toneladas (FAO, 2007).

No Brasil, a tilápia-do-Nilo (Oreochromis niloticus) foi introduzida em 1971. Com o objetivo de melhorar geneticamente o plantel, em 1996 foram importadas matrizes da linhagem tailandesa, gerando impactos positivos na produção de tilápia-do-Nilo, observando-se rápido crescimento em seu cultivo (KUBITZA, 2000; LOVSHIN, 2000).

Após a eclosão, a tilápia-do-Nilo, como a maioria dos peixes sedentários, apresenta rápido desenvolvimento de estruturas para captura de alimento, tais como olhos, nadadeiras, aparelho branquial etc. (MORRISON et al., 2001), e desenvolve-se bem no período larval, aceitando ração artificial (MEURER et al., 2005). Para se formular uma ração para larvas, além do balanço nutricional, deve-se levar em conta o seu processamento adequado, de modo que a dieta apresente propriedades que permitam o seu rápido consumo pelos animais (NRC, 1993), pois a sobra de ração aumenta a carga poluente na água de cultivo.

Rev. Acad., Ciênc. Agrár. Ambient., Curitiba, v. 7, n. 4, p. 415-421, out./dez. 2009 
No processamento de rações o grau de moagem reduz o tamanho das partículas, aumentando sua área de superfície, expondo maior área para a ação das enzimas digestivas (MONTICELLI et al., 1996). Além disso, quanto mais finamente moída é a ração, mais alto é o custo de produção, devido ao maior consumo de tempo e energia (NAKAGHI et al., 2009; MEURER et al., 2005).

Considerando a importância dessa espécie para a piscicultura e a falta de dados morfofuncionais de larvas, este trabalho teve por objetivo descrever o desenvolvimento da cavidade bucal da tilápia-do-Nilo com ênfase no tamanho e momento de abertura, a fim de se determinar o período ideal à ingestão de alimento exógeno. Ainda foram testadas granulometrias de ração adequadas, avaliando seus efeitos sobre o desempenho larval, tais como ganho de peso e crescimento.

\section{MATERIAL E MÉTODOS}

O experimento foi realizado no setor de Piscicultura do Centro de Aquicultura da Universidade Estadual Paulista (Caunesp) e no Laboratório de Microscopia Eletrônica da Faculdade de Ciências Agrárias e Veterinárias da Unesp, Campus de Jaboticabal.

Reprodutores de tilápias-do-Nilo (Oreochromis niloticus) foram acondicionados em seis tanques de alvenaria de 1.000 litros de capacidade e fluxo de água contínuo. Foram colocados dois machos e seis fêmeas em cada tanque, para que ocorresse a reprodução natural. Assim que verificados ovos na boca das fêmeas, essas foram retiradas do tanque e os ovos coletados por meio de contrafluxo de água na orofaringe, com auxílio de uma piceta. Os ovos de cada fêmea foram transferidos para incubadoras de 2 litros de capacidade, com fluxo de água contínuo. Após a observação do momento da eclosão das larvas, iniciaram-se as coletas dessas em intervalos de duas em duas horas, nos três primeiros dias, e de quatro em quatro horas nos demais dias, até um total de cinco dias de coletas.

Para realização do estudo do desenvolvimento do aparato bucal das larvas de tilápias foram utilizadas dez larvas de cada tempo amostrado. Essas foram fixadas em solução de Karnovsky por 24 horas, lavadas em tampão cacodilato de sódio $0,1 \mathrm{M} \mathrm{pH} \mathrm{7,4,} \mathrm{pós-fixadas} \mathrm{em} \mathrm{tetróxido} \mathrm{de} \mathrm{ósmio} \mathrm{a} \mathrm{1 \%} \mathrm{por}$ duas horas e lavadas novamente no mesmo tampão. Após desidratação em série crescente de etanol, foram processadas em secadora de ponto crítico com $\mathrm{CO}$ líquido, no aparelho BAL-TEC, montadas em suporte de cobre, metalizadas com ouro paládio e observadas em microscópio eletrônico de varredura (Jeol-JSM 5410). A morfometria da boca das larvas foi realizada em programa próprio do microscópio eletrônico de varredura Jeol Semafore - medidas em micrômetros (mm).

Para o período experimental, utilizou-se ração comercial contendo hormônio masculinizante (17-ametiltestosterona), sendo composta por 35\% PB, 5,19\% FB, 6,22\% EE e $4.130 \mathrm{Kcal} \mathrm{EB} / \mathrm{kg}$. Com os dados de medidas da boca obtidos, testou-se a eficiência dessa ração triturada e peneirada em três diferentes granulometrias $(0,21 \mathrm{~mm}, 0,35 \mathrm{~mm}$ e $0,50 \mathrm{~mm})$ no ganho de peso e crescimento dos peixes. Foi utilizado o delineamento inteiramente casualizado, com três tratamentos (granulometrias) e cinco repetições.

As larvas, com cinco dias de idade, foram contadas e transferidas das incubadoras para caixas plásticas com 130 litros de capacidade e 100 litros de volume útil de água, com aeração e fluxo contínuo nos diferentes tratamentos (80 larvas/caixa). As larvas foram privadas de alimento por um dia, para adaptação e redução do estresse de manejo. A ração foi oferecida quatro vezes ao dia, durante 30 dias. As caixas foram sifonadas diariamente e a temperatura da água mensurada duas vezes ao dia (manhã e tarde). Os parâmetros hídricos avaliados foram: $\mathrm{pH}$, temperatura, oxigênio dissolvido, condutividade e alcalinidade. A determinação da alcalinidade seguiu a metodologia de Goltermann et al. (1978) e os demais parâmetros foram obtidos por meio do aparelho Horiba U-10.

Após os 30 dias de tratamento com ração contendo hormônio masculinizante, os peixes foram coletados e fixados em formol tamponado a 10\%, para a biometria. Após a fixação, foram lavados em tampão cacodilato de sódio, colocados em placas de Petri, medidos com ocular micrométrica acoplada em estereomicroscópio Leica, modelo MZ8 e pesados em balança analítica Bel Mark 210 A.

Rev. Acad., Ciênc. Agrár. Ambient., Curitiba, v. 7, n. 4, p. 415-421, out./dez. 2009 
As análises estatísticas dos dados foram realizadas utilizando-se o programa estatístico SAS (Statistic Analysis System), versão 8.0 (SAS INSTITUTE, 2004).

\section{RESULTADOS}

Os valores médios dos parâmetros físico-químicos da água nos tanques experimentais, tais como $\mathrm{pH}$, temperatura, oxigênio dissolvido, condutividade e alcalinidade, foram respectivamente: 6,19; $25,05 \pm 1,0^{\circ} \mathrm{C} ; 4,56 \mathrm{mg} \cdot \mathrm{L}^{-1} ; 46,62 \mu \mathrm{S}$ e $28,75 \mathrm{mg}$. $\mathrm{CaCO}_{3} / \mathrm{L}$.

As larvas de tilápia-do-Nilo eclodiram com a boca fechada (Figura 1 - A). O tempo de abertura bucal iniciou-se com 8 horas pós-eclosão, e a partir de 24 horas a maioria das larvas já se encontrava com a boca totalmente aberta (Figura 1 - B e C).
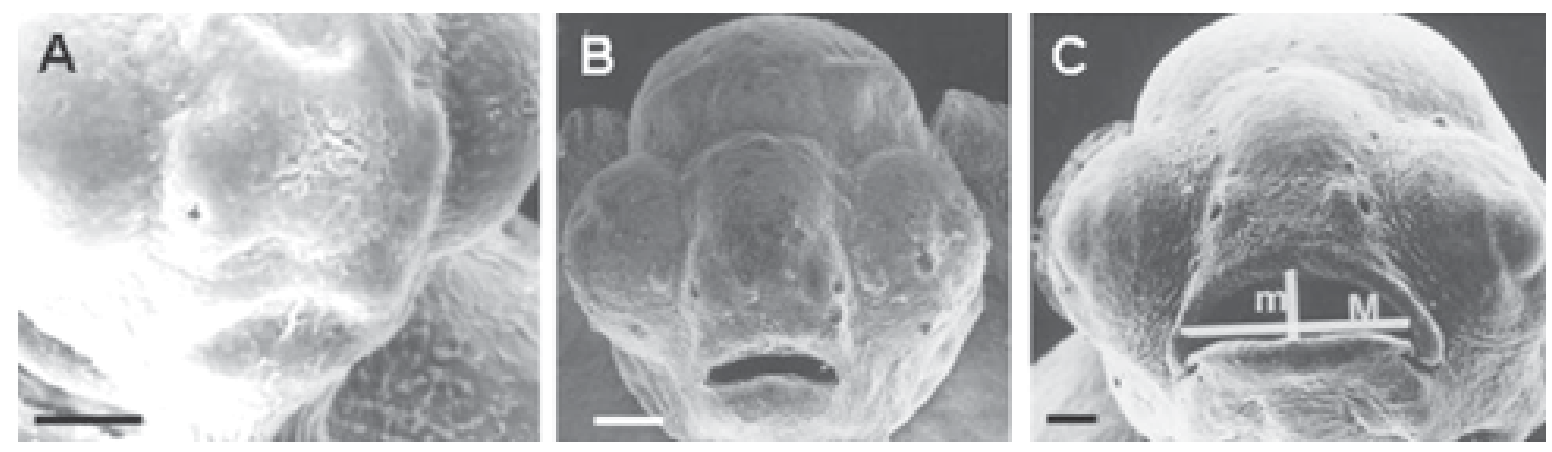

FIGURA 1 - Eletronmicrografia de varredura da larva de-tilápia-do-Nilo - (A) larva com a boca fechada (momento da eclosão), (B) larva com a boca aberta (24 horas pós-eclosão) e (C) larva com 32 horas pós-eclosão. Destaque para as medidas de comprimento $(\mathrm{M})$ e largura $(\mathrm{m})$ da boca da larva. (Barra=100 $\mu \mathrm{m}$ )

A medida da cavidade bucal realizada no microscópio eletrônico de varredura apresentou os seguintes resultados: largura no segundo dia pós-eclosão variou de 214 a $300 \mu \mathrm{m}$ e abertura de 114 a 128 $\mu \mathrm{m}$. No terceiro dia, a largura apresentou valores entre 314 a $400 \mu \mathrm{m}$ e abertura de 71 a $143 \mu \mathrm{m}$. No quarto dia, a largura variou de 257 a $443 \mu \mathrm{m}$ e a abertura de 71 a $157 \mu \mathrm{m}$. No último dia de coleta das larvas não foram realizadas medidas da abertura bucal, pois as larvas se encontravam com a boca apenas semiaberta no momento da fixação. Portanto, tomaram-se apenas as médias de largura, que apresentaram valores variando de $763 \mu \mathrm{m}$ a $1.031 \mu \mathrm{m}$.

Quanto ao desempenho, a Tabela 1 nos mostra dados médios de peso, comprimento total e comprimento padrão. Observou-se que o tratamento contendo ração de granulometria $0,21 \mathrm{~mm}$ apresentou médias significativamente mais baixas quando comparados aos tratamentos com ração de granulometria maior. Os tratamentos contendo rações com granulometria $0,35 \mathrm{~mm}$ e $0,50 \mathrm{~mm}$ não apresentaram diferenças significativas entre si.

TABELA 1 - Valores médios obtidos para as variáveis peso (g), comprimento total $(\mathrm{cm})$ e comprimento padrão (cm) para Oreochromis niloticus obtidas após alimentação com rações de diferentes granulometrias $(0,21,0,35$ e $0,50 \mathrm{~mm})$ por 30 dias

\begin{tabular}{cccc}
\hline Granulometria $(\mathbf{m m})$ & Peso $(\mathrm{g})$ & Comp. Total $(\mathbf{c m})$ & Comp. Padrão (cm) \\
\hline 0,21 & $0,404 \mathrm{a}$ & $2,643 \mathrm{a}$ & $2,090 \mathrm{a}$ \\
0,35 & $0,603 \mathrm{~b}$ & $3,093 \mathrm{~b}$ & $2,509 \mathrm{~b}$ \\
0,50 & $0,712 \mathrm{~b}$ & $3,096 \mathrm{~b}$ & $2,529 \mathrm{~b}$ \\
\hline
\end{tabular}

*As médias seguidas por letras diferentes (nas colunas) diferem entre si para valores de $\mathrm{p}<0,05$ (Teste de Tukey).

Rev. Acad., Ciênc. Agrár. Ambient., Curitiba, v. 7, n. 4, p. 415-421, out./dez. 2009 


\section{DISCUSSÃO}

A descrição do exato momento da abertura da boca em larvas de tilápia nilótica permite estabelecer o momento ideal para o início de fornecimento de ração exógena evitando desperdícios. No presente trabalho, larvas de tilápia nilótica apresentaram início da abertura bucal com aproximadamente 8 horas, e a partir de 24 horas pós-eclosão a boca se encontrava totalmente aberta na maioria das larvas. Algumas variações no tempo de desenvolvimento podem ocorrer, devido a condições ambientais e de temperatura, porém neste caso, como as condições foram as mesmas, provavelmente essas diferenças se devam a características dos reprodutores, como idade, tamanho, condições fisiológicas e genética (LEME DOS SANTOS, 1995; MORRISON et al., 2001).

Morrison et al. (2001), descrevendo o desenvolvimento larval da tilápia nilótica em microscopia de luz, estabeleceu a abertura da boca em torno de 22 horas pós-eclosão. Já Galman e Avtalion (1989), em microscopia eletrônica de varredura, descreveram boca aberta com aproximadamente 26 horas pós-eclosão.

Shaw e Aronson (1954) apud Morrison (2001) encontraram a boca aberta em Oreochromis macrocephalus antes mesmo da eclosão. Antes da abertura da boca as larvas se nutrem do vitelo, que é absorvido através de endocitose via camada sincicial do vitelo (SHAHSAVARANI, et al., 2002). Para evitar mortalidade das larvas e desperdício de ração, a alimentação exógena deve se iniciar com o vitelo completamente absorvido (TENGJAROENKUL et al., 2002).

Em diversas espécies, o tubo digestório muitas vezes ainda se encontra fechado, mesmo com a boca já aberta, como observado em Brycon amazonicus, por Neumann (2008), e em Astronotus ocellatus, por Paes (2008). Em Ciclídeos, as larvas apresentam estômago funcional antes da mudança da alimentação endógena para exógena (GORDON; HECHT, 2002).

Estudos sobre a compatibilidade do tamanho da boca de alevinos com a granulometria da ração oferecida são de extrema importância para a sobrevivência de larvas de peixes durante as fases iniciais da alimentação exógena. Nesse sentido, o conhecimento acerca do tempo em que ocorre a absorção do vitelo e o início da alimentação exógena pode subsidiar o oferecimento de alimento compatível com o desenvolvimento larval, reduzindo assim sua mortalidade nessa fase, uma vez satisfeitas outras necessidades ambientais da espécie (NEUMANN, 2008).

No presente trabalho, o valor médio dos diâmetros maior e menor aumentou gradativamente, até atingir, no quinto dia, valores médios de $763 \mu \mathrm{m}$ a $1.031 \mu \mathrm{m}$ para a largura. Dentre os três tratamentos testados, o que continha ração de granulometria $0,21 \mathrm{~mm}$ apresentou médias de peso e comprimento significativamente mais baixas, e os tratamentos de 0,35 e $0,50 \mathrm{~mm}$ não diferiram entre si. Assim, rações de granulometria $0,21 \mathrm{~mm}$ não são recomendadas para alimentação de tilápias nilóticas com início de alimentação exógena aos cinco dias de idade, não só por apresentarem desempenho zootécnico inferior, mas também por seu processamento despender mais energia, o que torna seu custo mais alto. Segundo Meurer et al. (2005), o uso de rações com granulometria $0,50 \mathrm{~mm}$ apresenta maior eficiência teórica para ganho de peso e comprimento em tilápias-do-Nilo com início de alimentação aos três dias de idade. Makino (2005) e Nakaghi et al. (2009) não encontraram diferenças estatísticas para comprimento total e ganho de peso em juvenis com alimentação iniciada aos cinco dias de idade e com rações de 0,25; 0,35 e 0,50 mm. Soares et al. (2003) recomendaram o uso de ração peletizada com granulometria de $0,79 \mathrm{~mm}$ para tilápias nilóticas em fase inicial de crescimento. Já Hayashi et al. (1999), testando diferentes tamanhos de ração para tilápias-doNilo, verificaram que a granulometria de $0,50 \mathrm{~mm}$ apresentou melhores resultados de desempenho.

\section{CONCLUSÕES}

Diante dos resultados obtidos, foi possível afirmar que no primeiro dia PE não houve necessidade de fornecer alimento exógeno, pois as larvas eclodiram com a boca fechada. Contudo, o desenvolvimento do aparelho bucal foi rápido, sendo possível a passagem de todas as granulometrias testadas a partir do quinto dia pós-eclosão.

Rev. Acad., Ciênc. Agrár. Ambient., Curitiba, v. 7, n. 4, p. 415-421, out./dez. 2009 
Com relação à granulometria das rações testadas, pode-se inferir que os peixes tratados com a granulometria $0,21 \mathrm{~mm}$ não apresentaram resultados favoráveis no tocante ao crescimento e engorda. Já as rações com granulometrias $0,35 \mathrm{~mm}$ e $0,50 \mathrm{~mm}$ tiveram respostas positivas, sendo recomendadas a partir do quinto dia pós-eclosão, e também por serem rações de preparo mais prático e menos custoso do que as de granulometrias mais finas.

\section{AGRADECIMENTOS}

Os autores são gratos à Fapesp (processos: 00/02199-9 e 01/13562-0) e ao Centro de Aquicultura da Unesp (Caunesp), pelas instalações e concessão dos animais destinados aos experimentos.

\section{REFERÊNCIAS}

FOOD AND AGRICULTURE ORGANIZATION OF THE UNITED NATIONS - FAO. 2007. Global Aquaculture Production 1950 - 2007. Available from: <http://www.fao.org/fishery/ statistics/global-aquaculture-production/query/en>. Access in: 22 Set. 2009.

GALMAN, O. R.; AVTALION, R. R. Further study of the embryonic development of the Oreochromis niloticus (Ciclidae, teleostei) using scanning electron microscopy. Journal of Fish Biology, London, v. 34, n. 5, p. 653-664, 1989.

GOLTERMANN, H. L. et al. Methods for physical and chemical analysis of freshwaters. London: Blackwell Science Publication, 1978.

GORDON, A. K.; HECHT, T. Histological studies on the development of the digestive system of the clownfish Amphiprion percula and the time of weaning. Journal of Applied Ichthyology, Berlin, v. 18, n. 2, p. 113-117, 2002.

HAYASHI, C. et al. Uso de diferentes graus de moagem dos ingredientes em dietas para tilápiado-Nilo (Oreochromis niloticus) na fase de crescimento. Acta Scientiarum: Animal Science, Maringá, v. 21, p. $733-737,1999$.

KUBITZA, F. Tilápia: tecnologia e planejamento na produção comercial. Jundiaí: F. Kubitza, 2000. 285 p.

LEME DOS SANTOS, H. S. Anatomia microscópica dos ovos de teleósteos nas diferentes etapas do desenvolvimento embrionário. In: SEMANA SOBRE HISTOLOGIA DE PEIXES DA FCAVJUNESP, 2., 1995, Jaboticabal. Anais... Jaboticabal: FUNEP, 1995. p. 153.

LEONHARDT, J. H.; URBINATTI, E, C. Estudo comparativo do crescimento entre machos de tilápia-do-Nilo, Oreochromis niloticus, sexados e revertidos. Boletim do Instituto de Pesca, São Paulo, v. 25, p. 19-26, 1999.

LOVSHIN, L. L. Tilapia culture in Brazil. In: COSTA-PIERCE, B. A.; RAKOCY, J. E. (Ed.). Tilapia aquaculture in the Americas. Louisiana: The World Aquaculture Society, 2000. v. 2, p. 133-140.

MAKINO, L. C. Validação dos métodos de identificação do sexo em tilápias-do-Nilo (Oreochromis niloticus) revertidas com rações contendo diferentes granulometrias e de diferentes idades. 2005. 31 f. Dissertação (Mestrado em Aquicultura) - Centro de Aquicultura da Universidade Estadual Paulista, Jaboticabal, 2005.

Rev. Acad., Ciênc. Agrár. Ambient., Curitiba, v. 7, n. 4, p. 415-421, out./dez. 2009 
MEURER, F. et al. Grau de moagem dos alimentos em rações para a tilápia-do-Nilo (Oreochromis niloticus) durante o período de reversão sexual. Acta Scientiarum: Animal Sciences, Maringá, v. 27, n. 1, p. $81-85,2005$.

MONTICELLI, C. J. et al. Efeito da granulometria do milho, da área por animal e do sexo sobre o desempenho de suínos em crescimento e terminação. Revista Brasileira de Zootecnia, Viçosa, v. 25 , n. 6 , p. $1150-1162,1996$.

MORRISON, C. M. et al. Histological study of the development of the embryo and early larva of Oreochromis niloticus (Pisces: Cichlidae). Journal of Morphology, Munich, v. 247, n. 3, p. 172-195, 2001.

NAKAGHI, L. S. O. et al. Sexagem histológica e desempenho de Oreochromis niloticus testando diâmetros de ração de acordo com o aparato bucal. Arquivo Brasileiro de Medicina Veterinária e Zootecnia, Belo Horizonte, v. 61, n. 3, p. 721-727, 2009.

NATIONAL RESEARCH COUNCIL - NCR. Nutrient requirement of fish. Washington: National Academy Press, 1993.

NEUMANN, E. Desenvolvimento inicial da jatuarana, Brycon amazonicus (Teleostei, Characidae). 2008. 125 f. Tese (Doutorado em Aquicultura) - Centro de Aquicultura, Universidade Estadual Paulista, Jaboticabal, 2008.

PAES, M. C. F. Indução à reprodução e desenvolvimento embrionário e larval do ciclídeo acará-açu, Astronotus ocellatus (Agassiz, 1831). 2008. 64 f. Dissertação (Mestrado em Aquicultura) - Centro de Aquicultura, Universidade Estadual Paulista, Jaboticabal, 2008.

SHAHSAVARANI, I. A. et al. A novel technique for the separation of yolk from the developing embryonic tissue in a teleost fish, Oncorbynchus mykiss. Fish Physiology and Biochemistry, Namur, v. 24 , n. 4 , p. 321-326, 2002.

SOARES, C. M. et al. Diferentes graus de moagem dos ingredientes em dietas peletizadas para a tilápia-do-Nilo (Oreochromis niloticus L.) em fase de crescimento. Desempenho e digestibilidade aparente. Zootecnia Tropical, Maracay, v. 21, n. 3, p. 275-287, 2003.

TENGJAROENKUL, B. et al. Ontogenic development of the intestinal enzymes of cultured Nile tilapia, Oreochromis niloticus L. Aquaculture, Amsterdam, v. 211, n. 1-4, p. 241-251, 2002.

Recebido: 17/07/2009

Received: 07/17/2009

Aprovado: 06/08/2009

Approved: 08/06/2009 